\title{
EFFECT OF CALCINATION TEMPERATURE ON THE STRUCTURE AND CATALYTIC PERFORMANCE OF THE CU-MCM-41 CATALYSTS FOR THE SYNTHESIS OF DIMETHYL CARBONATE
}

\author{
Yongjie Ding, ${ }^{\mathrm{a}, \mathrm{b}}$, Chunxiang Zhao, ${ }^{\mathrm{a}, *}$, Yunlin $\mathrm{Li}^{\mathrm{a}}$, Zheng $\mathrm{Ma}^{\mathrm{a}}$ and Xuelin $\mathrm{Lv}^{\mathrm{a}}$ \\ aCollege of Chemistry and Chemical Engineering, Zhoukou Normal University, Zhoukou 466001, P. R. China \\ ${ }^{b}$ Henan Key Laboratory of Rare Earth Functional Materials, Zhoukou Normal University, Zhoukou 466001, P. R. China
}

Recebido em 09/07/2018; aceito em 03/09/2018; publicado na web em 24/09/2018

\begin{abstract}
A series of Cu-MCM-41 catalysts were synthesized through in-situ hydrothermal preparation method, calcinated at different temperatures and characterized by thermogravimetric and differential scanning calorimetry (TG-DSC), $\mathrm{N}_{2}$ adsorption-desorption, X-ray diffraction (XRD), Fourier transform infrared spectroscopy (FI-IR), transmission electron microscopy (TEM) and hydrogen temperature-programmed $\left(\mathrm{H}_{2}\right.$-TPR). The effect of calcination temperature on the structural properties and selective oxidation of dimethoxymethane (DMM) to dimethyl carbonate (DMC) were discussed in detail. The results showed that the calcination temperature played important role on the microstructure and catalytic activity of the Cu-MCM-41 catalysts. At the calcination temperature $550^{\circ} \mathrm{C}$, the $\mathrm{Cu}-\mathrm{MCM}-41$ catalyst possessed higher surface area, smaller pore diameter, stronger metal-support interaction, and better $\mathrm{CuO}$ dispersion compared the other catalysts, and the corresponding catalyst exhibited excellent activity and stability for the DMC synthesis. Under the reaction conditions at $2.0 \mathrm{MPa}$ and $130{ }^{\circ} \mathrm{C}$, the highest DMM conversion was $99.47 \%$ with the best DMC selectivity of $85.01 \%$. In addition, the catalyst was reused four times without significant loss of performance.
\end{abstract}

Keywords: calcination temperature; Cu-MCM-41; dimethyl carbonate; dimethoxymethane.

\section{INTRODUCTION}

As an environmentally benign chemical, ${ }^{1}$ dimethyl carbonate (DMC) has attracted much attention of researchers worldwide for its widespread use in replacing harmful chemicals such as phosgene, ${ }^{2}$ dimethyl sulfate and chloroformate in organic syntheses. ${ }^{3,4}$ Moreover, DMC is used as a prospective fuel additive with high oxygen content and as an electrolyte in lithium batteries. ${ }^{5,6}$ Various methods have been used for DMC synthesis, such as phosgenation, ${ }^{7}$ oxidative carbonylation of methanol, ${ }^{8}$ direct synthesis from carbon dioxide and methanol, ${ }^{9}$ transesterification, ${ }^{10}$ urea methanolysis and selective oxidation of dimethoxymethane (DMM) ${ }^{11,12}$ The synthesis process of DMC from selective oxidation of DMM is regarded as one of the most attractive sustainable approaches owing to its simple, eco-friendly and high atom-economic. The reactive equation for the production of DMC is: $\mathrm{CH}_{2}\left(\mathrm{OCH}_{3}\right)_{2}+\mathrm{O}_{2} \rightarrow\left(\mathrm{CH}_{3} \mathrm{O}\right)_{2} \mathrm{CO}+\mathrm{H}_{2} \mathrm{O}$. To date, there have only been a limited number of studies on the route for DMC synthesis. In 1999, Wenger et al. found that the yield of major product DMC was $26 \%$ for the $\mathrm{Cl}$-atom initiated oxidation of DMM in the presence of $\mathrm{NO}_{x} \cdot{ }^{13}$ In 2010, Cu-based catalysts were used to catalyze the synthesis of DMC, $35 \%$ yield of DMC was achieved. ${ }^{14}$ These reports suffer from some problems such as the complicated preparation of catalysts and/or low production selectivity. In our previous work, $\mathrm{Cu}-\mathrm{MCM}-48$ catalysts exhibited a very high catalytic activity for the synthesis of DMC by selective oxidation of DMM with $\mathrm{O}_{2}$ (DMC yield, $82 \%$ ). ${ }^{12}$ To the best of our knowledge, no efficient catalysts were found for the selective oxidation of DMM except Cu-MCM-48 catalyst. Therefore, the development of another effective catalyst is a highly desirable for this important process.

Mesoporous materials MCM-41, belongs to the M41S family, has been utilized for several applications such as an adsorbent, catalyst support and development of sensors due to its high surface areas, ordered pore structure array and narrow pore size distribution. ${ }^{15,16}$ The transition metal ions such as $\mathrm{Al}, \mathrm{Cu}, \mathrm{V}, \mathrm{Fe}, \mathrm{Mn}$

\footnotetext{
*e-mail: chunxiangzhao@163.com
}

and Ti substituted MCM-41 materials have been synthesized and their catalytic performances have been explored. ${ }^{17}$ Several reports have demonstrated the use of MCM-41 incorporated $\mathrm{Cu}$ catalysts in wide range of reactions such as selective oxidation of phenol, ${ }^{18}$ selective catalytic reduction of $\mathrm{NO}$ using $\mathrm{NH}_{3},{ }^{19}$ steam reforming of methanol, ${ }^{20}$ etc. However, their utilization in oxidation of DMM has not yet been reported. In addition, it is well-known that the property of catalysts closely related with the preparation conditions, such as calcinations temperature. So in this study, $\mathrm{Cu}-\mathrm{MCM}-41$ samples were prepared by in-situ hydrothermal synthesis method, and the influence of calcination temperature on the microstructures and selective oxidation of DMM activities were studied in detail.

\section{MATERIALS AND METHODS}

\section{Catalysts preparation}

All $1 \mathrm{wt} \% \mathrm{Cu}-\mathrm{MCM}-41$ samples were prepared with tetraethyl orthosilicate (TEOS) as silica source, cetyltrimethylammonium bromide (CTAB) as template. ${ }^{12}$ For a typical synthesis, $0.59 \mathrm{~g} \mathrm{NaOH}$ and $1.06 \mathrm{~g} \mathrm{CTAB}$ were dissolved in deionized water and the solution was stirred at $35{ }^{\circ} \mathrm{C}$ for about $40 \mathrm{~min}$, and then $0.09 \mathrm{~g} \mathrm{CuNO}_{3} \cdot 3 \mathrm{H}_{2} \mathrm{O}$ was added into the resulting solution, followed by adding $9.2 \mathrm{~mL}$ TEOS slowly. The mixture was stirred for $1 \mathrm{~h}$ before being loaded into a Teflon-lined stainless steel vessel, where the mixture was kept at $110^{\circ} \mathrm{C}$ for $48 \mathrm{~h}$. The solid product was filtered, washed with deionized water, dried in air at $110{ }^{\circ} \mathrm{C}$ for $12 \mathrm{~h}$ to obtain as-synthesized sample. Finally, these samples were calcined in air at different temperatures $\left(250,350,450,550\right.$ and $\left.650{ }^{\circ} \mathrm{C}\right)$ for $6 \mathrm{~h}$. The calcined samples were designated as $\mathrm{Cu}-\mathrm{MCM}-41-\mathrm{T}$, where $\mathrm{T}$ represented the calcination temperature $\left({ }^{\circ} \mathrm{C}\right)$.

\section{Catalyst characterization}

Thermogravimetric and differential scanning calorimetry analyses (TG-DSC) were performed in a PerkinElmer STA-6000. The sample 
was loaded into an aluminum pan and heated to $800{ }^{\circ} \mathrm{C}$ at a heating rate of $10{ }^{\circ} \mathrm{C} / \mathrm{min}$ under $\mathrm{N}_{2}$ atmosphere.

The textural properties of the samples were analyzed by $\mathrm{N}_{2}$ adsorption-desorption isotherms obtained at $77 \mathrm{~K}$ using Micromeritics ASAP 2020 HD88 apparatus. The specific surface area was calculated by Brunauer-Emmett-Teller (BET) method. Pore size distribution and pore volume were calculated by Barrett-Joyner-Halenda (BJH) method.

The small and wide angle powder X-ray diffractions (XRD) were recorded on a Rigaku D/Max-2500 diffractometer with $\mathrm{Cu} \mathrm{K} \alpha$ radiation $(\lambda=0.15418 \mathrm{~nm})$. The measurement conditions of XRD at low angle were: $40 \mathrm{kV}, 50 \mathrm{~mA}$, the scanning range was $1.5-7.5^{\circ}$ and the scanning speed $1 \% \mathrm{~min}$; the measurement conditions of XRD at high angle were: $40 \mathrm{kV}, 200 \mathrm{~mA}$, the scanning range was $10-70^{\circ}$ and the scanning speed $4 \% \mathrm{~min}$.

Transmission electron microscopy (TEM) morphologies of samples were observed on a JEM-2010 with an acceleration voltage of $200 \mathrm{kV}$.

Fourier transform infrared (FI-IR) spectra were collected on a Thermo-Nicolet Nexus 670 FT-IR spectrometer by using conventional $\mathrm{KBr}$ pellet method.

Hydrogen temperature programmed reduction $\left(\mathrm{H}_{2}-\mathrm{TPR}\right)$ profiles of the samples were carried out on a PCA-1200 adsorption instrument made by Beijing Builder Electronic Technology. Typically, the U-tube quartz microreactor was loaded with $50 \mathrm{mg}$ catalyst along with quartz wool and heated at a temperature ramp from 25 to $700{ }^{\circ} \mathrm{C}$ at $5{ }^{\circ} \mathrm{C} \mathrm{min}{ }^{-1}$ with a gas consisting of $5 \% \mathrm{H}_{2}$ in Ar. The gas flow rate was $30 \mathrm{~mL} \mathrm{~min}^{-1}$. The $\mathrm{H}_{2}$ consumption (TCD signal) was recorded automatically by TCD detection.

\section{Catalytic reaction}

The oxidative reaction of DMM with molecular oxygen was conducted in a $200 \mathrm{~mL}$ stainless steel batch reactor. A typical reaction process was as follows: $40 \mathrm{mmol} \mathrm{DMM}$ were dissolved into the acetonitrile solvent $(40 \mathrm{~mL})$ in the reactor, and then $2 \mathrm{mmol}$ $\mathrm{N}$-hydroxyphthalimide (NHPI) used as inducing agent and $1 \mathrm{mmol}$ chlorobenzene as the internal standard agent for quantitative analysis were added into the solution. After that, $0.5 \mathrm{~g} \mathrm{Cu}-\mathrm{MCM}-41$ powders were added into the mixed solution above. Subsequently, the reactor was sealed after the reaction mixture was purged with $\mathrm{O}_{2}$ for $5 \mathrm{~min}$. Finally, the reactor with $2.0 \mathrm{MPa} \mathrm{O}_{2}$ was heated to $130{ }^{\circ} \mathrm{C}$ for $2 \mathrm{~h}$ under the magnetic stirring. At the end of the reaction, the products were analyzed with a GC9890A Gas Chromatographer (GC) equipped with a DB-WAX column and a flame ionization detector (FID).

\section{RESULTS AND DISCUSSION}

\section{Characterization of $\mathrm{Cu}-\mathrm{MCM}-41$}

\section{TG-DSC analysis}

Figure 1 showed the TG and DSC curves of the as-synthesized Cu-MCM-41 sample, which was thermal decomposed in $\mathrm{N}_{2}$. The TG curve of the uncalcined sample showed four main processes of weight loss at $30-200{ }^{\circ} \mathrm{C}, 200-280{ }^{\circ} \mathrm{C}, 280-500{ }^{\circ} \mathrm{C}$ and $>500{ }^{\circ} \mathrm{C}$. The weight loss in the first stage was related to vaporization of physically adsorbed water moleculers and/or organic structures. ${ }^{21}$ The significant mass loss during the second and third stages might be ascribed to decomposition of template and $\mathrm{Cu}(\mathrm{OH})_{2}$ to $\mathrm{CuO}$ in the silica matrix. The steady minimal weight loss which occurred above $500{ }^{\circ} \mathrm{C}$ could be ascribed to dehydroxylation or condensation of silanol groups to form the Si-O-Si-O-Si framework..$^{22}$ There were two independent exothermic peaks and one endothermic peak in DSC curve corresponding to the significant mass loss step in TG curve. The endothermic peak at $249^{\circ} \mathrm{C}$ detected in DSC curve was ascribed to the decomposition from surfactant. ${ }^{23}$ The first sharp exothermic peak at $296{ }^{\circ} \mathrm{C}$ was due to the combustion of remaining organic species, while the second exothermic peak at $435^{\circ} \mathrm{C}$ was associated with the decomposition of $\mathrm{Cu}(\mathrm{OH})_{2}$ and the condensation of silanol groups. ${ }^{24}$

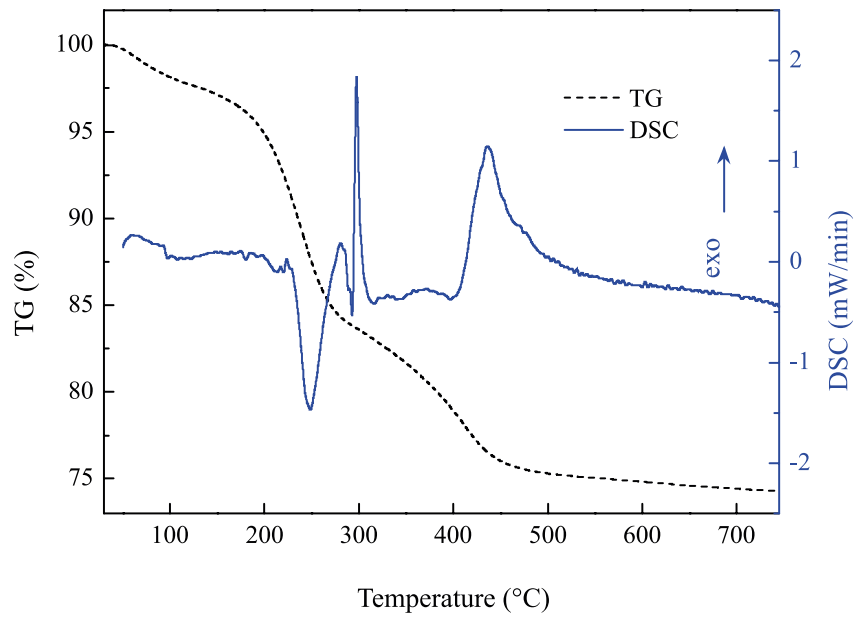

Figure 1. TG-DSC curves of the as-synthesized Cu-MCM-41 sample

\section{Textural properties}

Table 1 summarized the textural properties of the samples calcined at different temperatures. It could be observed that calcination temperature had a remarkable influence on the textural properties of the samples. When the calcination temperature of the catalysts increased from $250{ }^{\circ} \mathrm{C}$ to $650{ }^{\circ} \mathrm{C}$, the specific surface area increased initially from $860 \mathrm{~m}^{2} / \mathrm{g}$ to $992 \mathrm{~m}^{2} / \mathrm{g}$, and subsequently decreased sharply to $288 \mathrm{~m}^{2} / \mathrm{g}$. On the contrary, the pore diameter decreased firstly and then increased. Nevertheless, it was evident that the pore volume decreased with increasing calcination temperature. Because of the decomposition of organic template, many new pores were formed during the calcination processes, which resulted in higher surface area and lower pore diameter (the catalyst calcined at $550{ }^{\circ} \mathrm{C}$ ). However, the higher calcination temperature could make the pore collapsed, the sintering of particles and blockage of smaller pores, which led to the surface area declined, the pore volume decreased and the pore diameter increased (the catalyst calcined at $650{ }^{\circ} \mathrm{C}$ ). ${ }^{25}$

Table 1. Properties of the Cu-MCM-41 catalysts calcined at different temperatures

\begin{tabular}{cccc}
\hline $\mathrm{T}_{\text {calcination }}\left({ }^{\circ} \mathrm{C}\right)$ & $\mathrm{S}_{\mathrm{BET}}\left(\mathrm{m}^{2} / \mathrm{g}\right)$ & $\begin{array}{c}\text { Pore volume } \\
\left(\mathrm{cm}^{3} / \mathrm{g}\right)\end{array}$ & $\begin{array}{c}\text { Pore diameter } \\
(\mathrm{nm})\end{array}$ \\
\hline 250 & 860 & 0.83 & 3.86 \\
550 & 992 & 0.62 & 2.50 \\
650 & 288 & 0.46 & 6.40 \\
\hline
\end{tabular}

The $\mathrm{N}_{2}$ adsorption-desorption isotherms (a) and $\mathrm{BJH}$ pore size distribution plots (b) of the samples calcined at different temperatures were presented in Figure 2. The obtained isotherms exhibited the IV-type isotherm with the hysteresis loop (based on the empirical IUPAC classification) ${ }^{26}$ The point of inflection at relative pressure of $\left(\mathrm{P} / \mathrm{P}_{0}=0-0.2\right)$ represents the completion of monolayer coverage. The sharp inflection seen from $\mathrm{P} / \mathrm{P}_{0}=0.2-0.4$ corresponds to typical capillary condensation with uniform mesopores. The steepness of this step emphasizes the narrow ordered pore size distribution of the samples. ${ }^{27}$ It was worth noting that the sample of calcination 

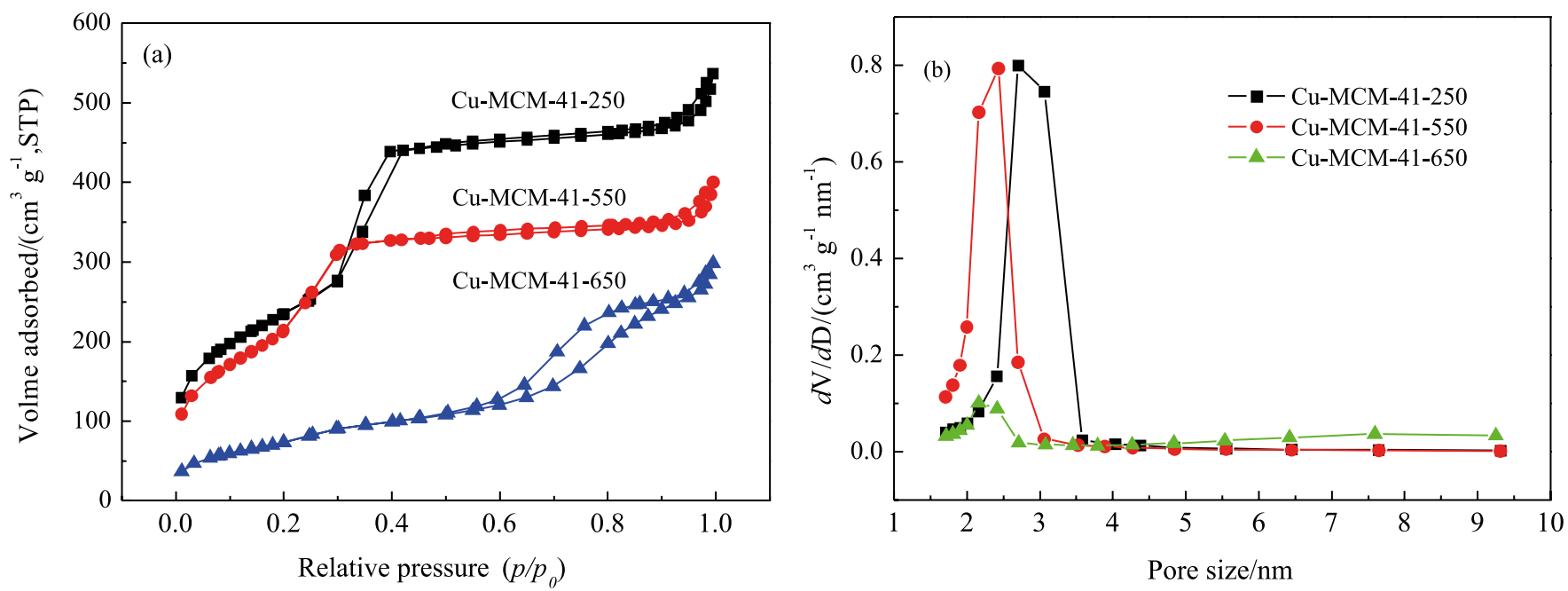

Figure 2. $\mathrm{N}_{2}$ adsorption-desorption isotherms (a) and pore size distribution (b) of the Cu-MCM-41 catalysts calcined at different temperatures

temperature at $550{ }^{\circ} \mathrm{C}$ exhibited no hysteresis loop in this step $\left(\mathrm{P} / \mathrm{P}_{0}=0.2-0.3\right)$, suggesting more narrow pore size distribution (pore sizes from 2 to $3 \mathrm{~nm}$ ). For the sample of calcination temperature at $650^{\circ} \mathrm{C}$, there was not obvious sharpness of the pore filling step in the step $\left(\mathrm{P} / \mathrm{P}_{0}=0.2-0.4\right)$, indicating the widening of pore size distribution as shown in Figure 2(b), ${ }^{20}$ further suggesting some loss of the ordered structure with increasing calcination temperature. A long plateau at high relative pressures $\left(\mathrm{P} / \mathrm{P}_{0}=0.4-0.9\right)$ was attributed to the multilayer absorption. Finally, the sharp $\mathrm{N}_{2}$ absorption with a small hysteresis loop at higher relative pressures $\left(\mathrm{P} / \mathrm{P}_{0}>0.9\right)$ suggested condensation of $\mathrm{N}_{2}$ in the interparticle pores. ${ }^{28}$

\section{$X$-ray diffraction}

Small angle X-ray diffraction patterns of $\mathrm{Cu}-\mathrm{MCM}-41$ samples with different calcination temperature were shown in Figure 3a. The as-synthesized $\mathrm{Cu}-\mathrm{MCM}-41$ sample exhibited a strong peak, at $2 \theta=2.16^{\circ}$ due to $(100)$ reflection lines and three weak signals around $3.70^{\circ}, 4.24^{\circ}$ and $5.64^{\circ}(2 \theta)$ corresponding to (110), (200) and (210) reflections, indicating the formation of well-ordered mesoporous materials with hexagonal regularity. ${ }^{29}$ The main peaks of the XRD patterns of the samples were consistent with the characteristic peaks of the hexagonal structure of the MCM-41 mesoporous molecular sieves when calcination temperature was in the range from 250 to $550{ }^{\circ} \mathrm{C}$. The $2 \theta$ positions were shifted to a higher value with

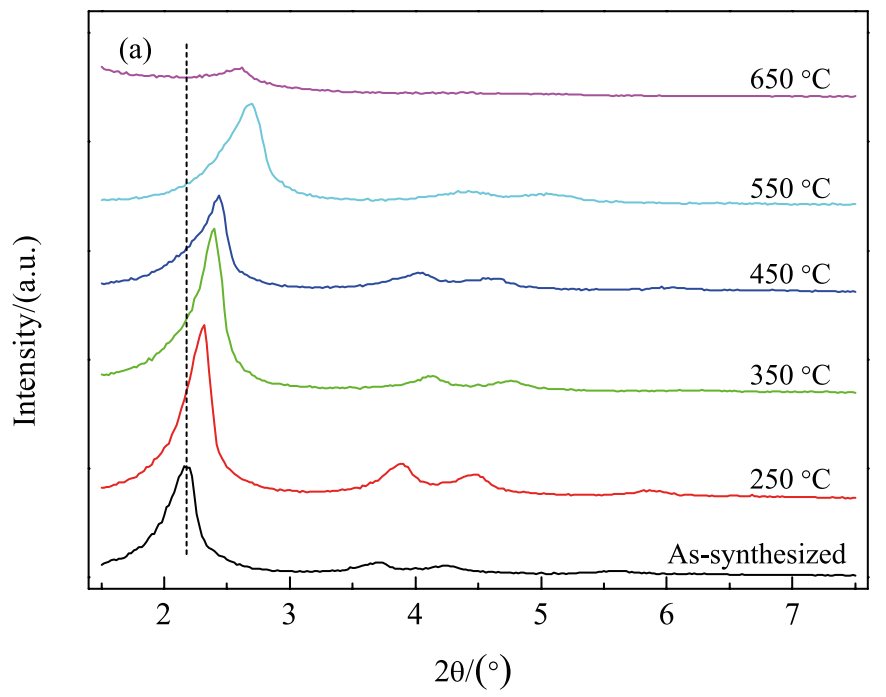

increasing the calcination temperature, revealing a decrease in the $d_{100}$ spacing, which might be related to the removal of used template and subsequent condensation of the silanol groups. ${ }^{30}$ Moreover, the intensity of the main (100) reflection of the Cu-MCM-41-650 sample sharply decreased and other reflections (110, 200 and 210) could not be observed, which indicated the ordered structure partially collapsed leading to a relatively disordered mesostructure at higher temperature. ${ }^{31}$ The textural properties of the Cu-MCM-41-650 sample listed in Table 1 proved the conclusion. Meanwhile, this observation confirmed the argument that there was an unobvious sharpness of the pore filling step of the BET isotherm (Figure 2) in the step $\left(\mathrm{P} / \mathrm{P}_{0}=0.2-0.4\right)$ due to the decreased long rang order in MCM-41.

Figure 3(b) showed the wide angle X-ray diffraction patterns at higher angles of $\mathrm{Cu}-\mathrm{MCM}-41$ samples with different calcination temperature. The XRD spectra of samples calcined temperature above $450^{\circ} \mathrm{C}$ exhibited two weak diffraction peaks at $2 \theta$ values around $35.6^{\circ}$ and $38.9^{\circ}$ attributed to the $\mathrm{CuO}$ crystallites phasen. ${ }^{32}$ Meanwhile, the intensity of the diffraction peaks increased with increasing calcination temperature, which indicated the slight aggregation of copper oxide species. This result was well consistent with the TG-DSC results.

\section{FT-IR spectra analysis}

The FT-IR spectra of Cu-MCM-41 samples calcined at different temperature were shown in Figure 4. The wide absorption band

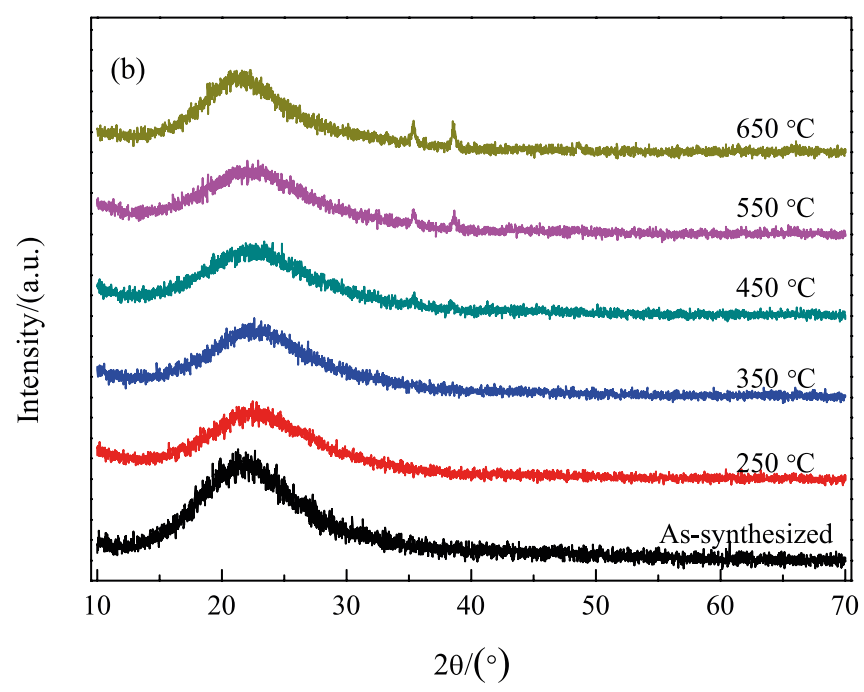

Figure 3. Small angle XRD patterns (a) and wide angle XRD patterns $(b)$ of Cu-MCM-41 samples calcined at different temperatures 
between 3600 and $3200 \mathrm{~cm}^{-1}$ and the absorption band centering at $1630 \mathrm{~cm}^{-1}$ observed for all samples could be due to the $\mathrm{O}-\mathrm{H}$ bond stretching and bending vibrations of silanol groups and/or adsorbed moisture on the support. ${ }^{33}$ Samples calcined at $250-550{ }^{\circ} \mathrm{C}$ showed the characteristic bands at around 1090 (shoulder at 1239), 801 and $464 \mathrm{~cm}^{-1}$, which corresponded to the anti-symmetric, symmetric $\mathrm{Si}-\mathrm{O}$ stretching and the deformation modes of $\mathrm{SiO}_{4}$ tetrahedra in the $\mathrm{Si}-\mathrm{O}-\mathrm{Si}$ structure, respectively. ${ }^{33,34}$ The peak at $965 \mathrm{~cm}^{-1}$ was assigned to the perturbation induced in $\left[\mathrm{SiO}_{4}\right]$ which could be related to the replacement of heteroatoms, the nature of compensation cation and silanol and/or siloxy defect sites. ${ }^{35}$

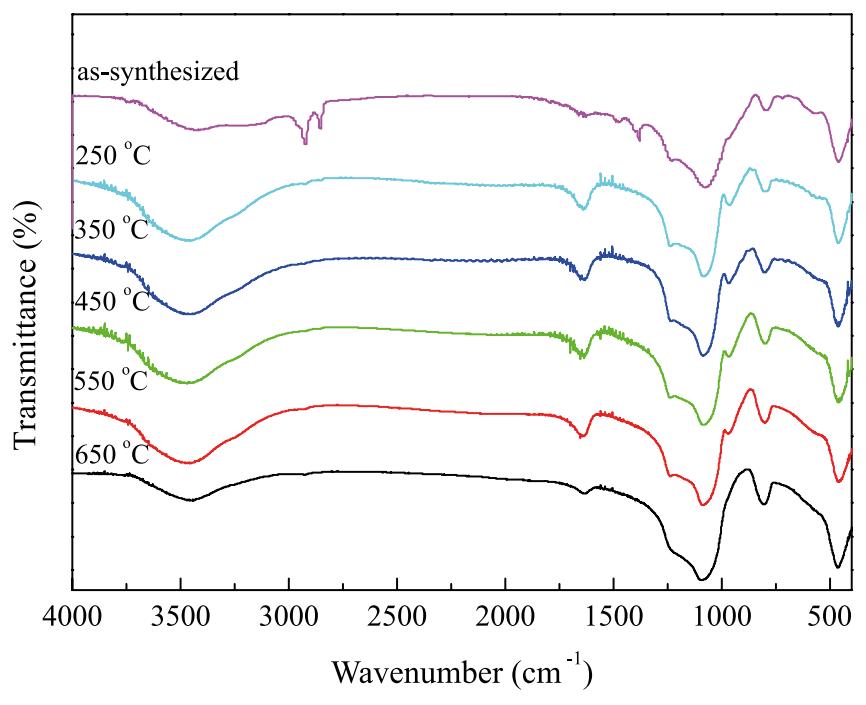

Figure 4. FT-IR spectra of Cu-MCM-41 samples calcined at different temperatures

\section{TEM analysis}

The TEM images of the Cu-MCM-41 samples with different calcination temperature were shown in Figure 5. The TEM images of the as-synthesized Cu-MCM-41, Cu-MCM-41-250 and Cu-MCM-41-550 samples exhibited well ordered long range array which were also consistent with the results obtained from the small angle XRD analysis. This revealed that the mesoporous structure was largely preserved and did not change dramatically when calcined temperature below $550{ }^{\circ} \mathrm{C}$. Meanwhile, there were no visible $\mathrm{CuO}$ deposits in TEM images of Cu-MCM-41 samples, indicating well dispersion of copper species within the framework of Cu-MCM-41 structures. ${ }^{36}$ However, the TEM image of Cu-MCM-41-650 sample revealed the loss of long range order, it was possible to determine that higher calcination temperature destroyed the structure of mesopores which was consist with the XRD data.

\section{$\mathrm{H}_{2}-\mathrm{TPR}$ analysis}

The $\mathrm{H}_{2}$-TPR profiles of $\mathrm{Cu}-\mathrm{MCM}-41$ samples calcined at different temperatures were shown in Figure 6. It could be observed that the redox properties of samples were strongly affected by the calcination temperature. The sample calcined at $250{ }^{\circ} \mathrm{C}$ consisted of two reduction peaks at around $238{ }^{\circ} \mathrm{C}$ (the main peak) and $264{ }^{\circ} \mathrm{C}$ (the shoulder peak), indicating the stepwise reduction process of $\mathrm{Cu}^{2+}$ to $\mathrm{Cu}^{0}{ }^{37}$ Analysis of TPR profiles shown in Figure 6 further revealed that the $\mathrm{CuO}$ reduction peak exhibited a prominent shift toward higher temperature with increasing temperature of calcination and had the greatest effect on overall TPR curve shape. It had been reported that the increase of the reduction temperature was related to a strong metal support interaction, which decreased dispersion and in turn affected the catalytic performance. ${ }^{38}$ These results indicated the

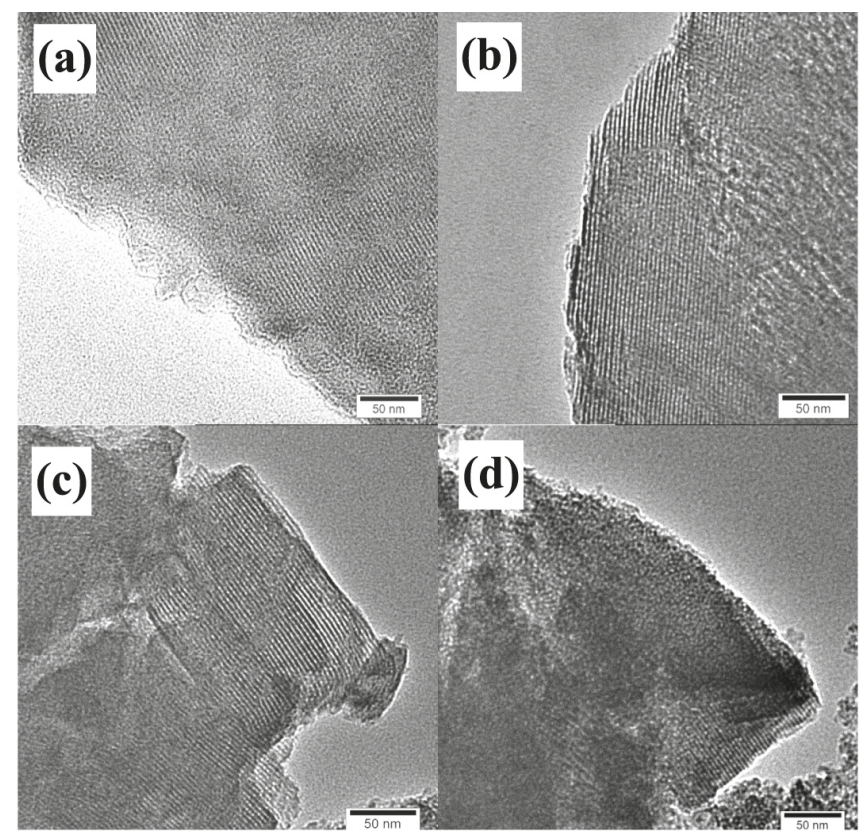

Figure 5. The TEM images of (a) as-synthesized Cu-MCM-41; (b) Cu-MCM-41-250; (c) Cu-MCM-41-550 and (d) Cu-MCM-41-650

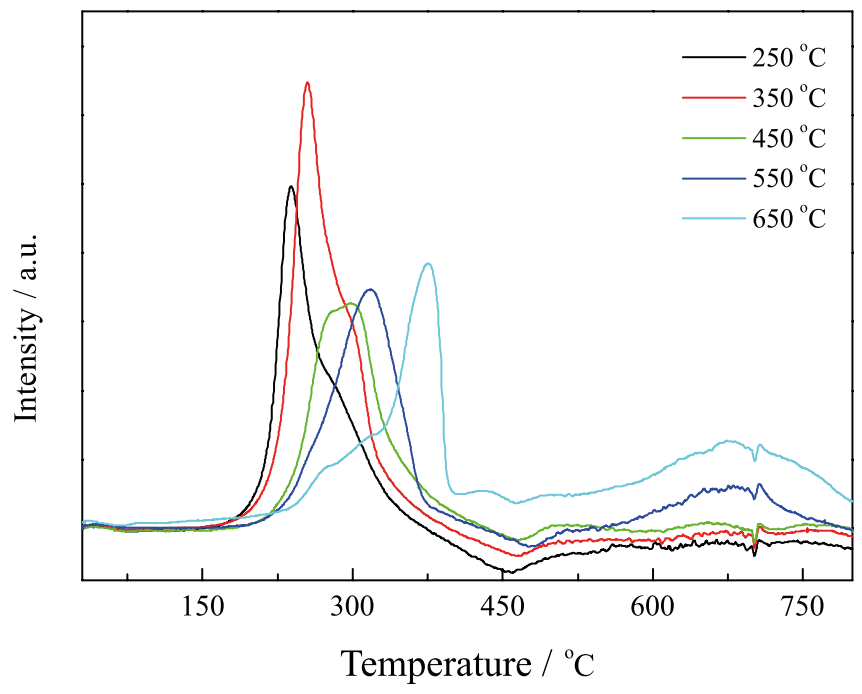

Figure 6. $\mathrm{H}_{2}-\mathrm{TPR}$ profiles of $\mathrm{Cu}-\mathrm{MCM}-41$ samples calcined at different temperatures

strong interaction between $\mathrm{Cu}$ species and MCM-41. The reduction peak at higher temperature could be attributed to the reduction of the body phase of copper species or the crystalline $\mathrm{CuO}$. With increasing calcination temperatures, the main reduction peaks of $\mathrm{Cu}-\mathrm{MCM}-41$ shifted to higher temperatures, implying that the redox activities of catalysts were reduced by the higher calcination temperature. ${ }^{39}$

\section{Catalytic oxidation reaction of DMM with $\mathrm{O}_{2}$}

The catalytic activity of various $\mathrm{Cu}-\mathrm{MCM}-41$ catalysts was evaluated in the oxidation of DMM with $\mathrm{O}_{2}$ to DMC (Figure 7). In the reaction system, the target product was DMC and the main by-products were methyl formate $(\mathrm{MeF})$, methanol $(\mathrm{MeOH})$, methaoxymethyl formate (MMF). Our previous study showed that there was no significant conversion of DMM (only 6.80\%) in the absence of catalyst. ${ }^{12}$ The results of Figure 7 showed that $78.00 \%$ of the DMM conversion and $61.20 \%$ of DMC selectivity were obtained 

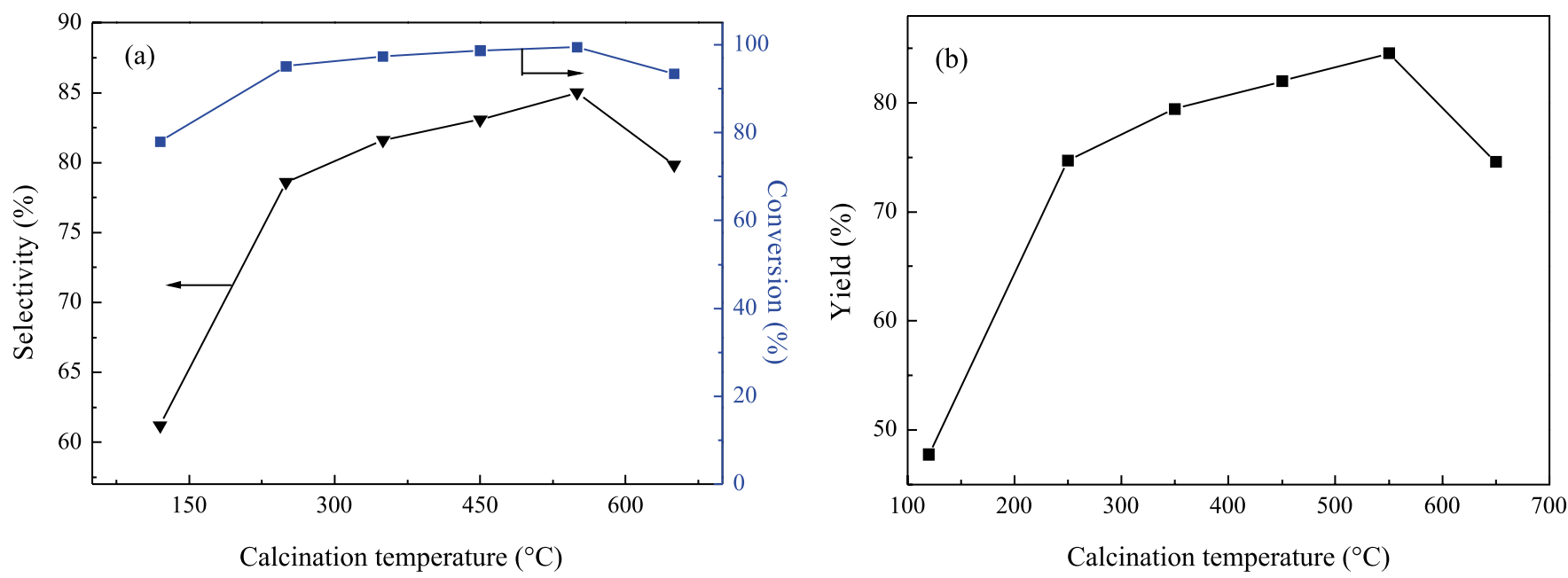

Figure 7. Catalytic performances of the $\mathrm{Cu}-\mathrm{MCM}-41$ catalysts calcined at different temperatures. Reaction conditions: $\mathrm{Cu}-\mathrm{MCM}-41 \mathrm{O} .5 \mathrm{~g}, \mathrm{O}_{2} \mathrm{pressure} 2 \mathrm{MPa}$, reaction time $2 \mathrm{~h}$, temperature $160^{\circ} \mathrm{C}$

over the uncalcinated catalyst. Compared with uncalcinated catalyst, all the calcinated catalysts displayed a DMM conversion above $93.00 \%$, and the superior conversion was $99.47 \%$ (Cu-MCM-41-550). The selectivity of DMC presented "bell-shape" change with the calcination temperatue of the catalyst from $250-650{ }^{\circ} \mathrm{C}$, and the $\mathrm{Cu}-\mathrm{MCM}-41-550$ revealed the best selectivity of DMC (85.01\%). Thus, the $\mathrm{Cu}-\mathrm{MCM}-41-550$ catalyst exhibited favorable catalytic activity for the synthesis of DMC from DMM and $\mathrm{O}_{2}$. These results indicated that the calcination temperature would greatly affect the catalytic efficiency of the Cu-MCM-41 catalysts. Exceedingly high or low calcination temperatures generate poor catalytic performance.

According to the literature, the calcination process played an important role in the structural evolution and metal dispersion. ${ }^{40}$ As shown in characterization of $\mathrm{Cu}-\mathrm{MCM}-41$, with the calcination temperature increased, the specific surface area increased initially and subsequently decreased, on the contrary, the pore diameter decreased firstly and then increased. High surface area could provide sufficient active sites for catalysis. Small pore of the catalyst could make the small reactant/product molecules diffuse freely, ${ }^{41}$ which resulted in the selectivity of product increased. However, the uncalcinated Cu-MCM-41 catalyst exhibited $78.00 \%$ of the DMM conversion, although it possessed poor surface area compared to the calcined catalysts. ${ }^{42}$ Meanwhile, the catalytic activities showed nonlinear increase or decrease with the change of specific surface area. For example, DMC yield increased from $74.75 \%$ for $\mathrm{Cu}-\mathrm{MCM}-41-250$ (surface area, $860 \mathrm{~m}^{2} / \mathrm{g}$ ) to $84.56 \%$ for $\mathrm{Cu}-\mathrm{MCM}-41-550$ (surface area, $992 \mathrm{~m}^{2} / \mathrm{g}$ ), then decreased to $74.62 \%$ for Cu-MCM-41-650 (surface area, $288 \mathrm{~m}^{2} / \mathrm{g}$ ). Therefore, the surface area was not the decisive factor in the production of DMC. Our previous study showed that the species formed through intimate interaction between $\mathrm{Cu}$ and the support was the active center for the catalytic oxidation reaction of DMM with $\mathrm{O}_{2}{ }^{12}$ In the current $\mathrm{Cu}-\mathrm{MCM}-41-\mathrm{T}$ system, the metalsupport interaction was always existed. So the as-synthesized $\mathrm{Cu}-$ MCM-41 showed certain catalytic activity. Although the increase of the calcination temperature could enhance the metal-support interaction, ${ }^{43,44}$ excessively high calcination temperature would induce the sintering of particles, thereby affecting the catalytic activity. For the $\mathrm{Cu}-\mathrm{MCM}-41-650$ catalyst, the high calcination temperature caused poor copper dispersion and reduced the redox activities which resulted in the decreased activition of the catalyst.

The excellent catalytic performance of $\mathrm{Cu}-\mathrm{MCM}-41-550$ catalyst could be partly related to the highest surface area $\left(992 \mathrm{~m}^{2} / \mathrm{g}\right)$ and the lowest pore diameter $(2.5 \mathrm{~nm})$ compared the other catalysts. In addition, XRD results showed that the catalyst calcined at $550{ }^{\circ} \mathrm{C}$ exhibited better dispersion of active metals on the support, FT-IR spectra and $\mathrm{H}_{2}$-TPR profiles also illustrated the strong metal-support interaction in the catalyst calcined at $550^{\circ} \mathrm{C}$. Based on the relationship between the catalyst activity and its properties, the fact could be presumed that high surface area, small pore diameter, strong metalsupport interaction, and good $\mathrm{CuO}$ dispersion of the catalyst could be beneficial to catalytic activity.

Reusability of the catalyst was studied over the Cu-MCM-41-550 catalyst. Upon completion of the reaction, $\mathrm{Cu}-\mathrm{MCM}-41$ was recovered by simple filtration, then dried at $110^{\circ} \mathrm{C}$ for $2 \mathrm{~h}$ before use for the next cycle. Figure 8 suggested that the catalyst could be reused four times without a significant loss of catalytic activity.

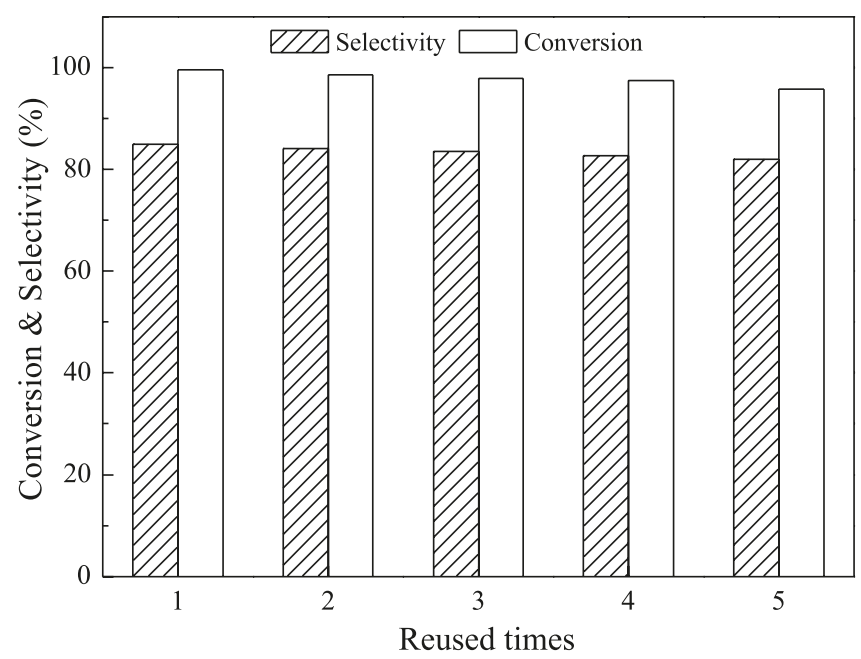

Figure 8. Reusability of the Cu-MCM-41-550 catalyst. Reaction conditions: Cu-MCM-41 $0.5 \mathrm{~g}, \mathrm{O}_{2}$ pressure $2 \mathrm{MPa}$, reaction time $2 \mathrm{~h}$, temperature $160^{\circ} \mathrm{C}$

\section{CONCLUSIONS}

A series of $\mathrm{Cu}-\mathrm{MCM}-41$ catalysts were synthesized through in-situ hydrothermal preparation method, calcinated at different temperatures and characterized with various techniques. The characterization results showed that the calcination temperature was essential to the microstructure of the $\mathrm{Cu}-\mathrm{MCM}-41$. The studies of the catalytic behavior of $\mathrm{Cu}-\mathrm{MCM}-41$ catalysts in the selective oxidation of DMM to DMC using $\mathrm{O}_{2}$ as the oxidant suggested that 
the optimized calciniation temperature of the catalyst was $550{ }^{\circ} \mathrm{C}$. At the calcination temperature $550{ }^{\circ} \mathrm{C}$, the $\mathrm{Cu}-\mathrm{MCM}-41$ catalyst possessed higher surface area, smaller pore diameter, stronger metalsupport interaction and better $\mathrm{CuO}$ dispersion compared the other catalysts, which was beneficial to improve the catalytic activity of the catalyst. Under the reaction conditions at $2.0 \mathrm{MPa}$ and $130{ }^{\circ} \mathrm{C}$, the highest DMM conversion was $99.47 \%$ with the best DMC selectivity of $85.01 \%$. In addition, the catalyst was reused four times without significant loss of performance.

\section{ACKNOWLEDGEMENTS}

This research was financially supported by the key project of Natural Science Basic Research Project of Education Department of Henan Province (No. 17A150057).

\section{REFERENCES}

1. Ono, Y.; Appl. Catal., A 1997, 155, 133.

2. Zheng, L. P.; Xia, S. X.; Lu, X. Y.; Hou, Z. Y.; Chin. J. Catal. 2015, 36, 1759.

3. Guo, J. H.; Xu, Z.; Liu, Y. F.; Wang, X. D.; Zhao, Y. Q.; Bioorg. Med. Chem. Lett. 2016, 26, 476.

4. Shi, J. H.; Liu, G.; Fan, Z. Q.; Nie, L. Y.; Zhang, Z. H.; Zhang, W. X.; Huo, Q. S.; Yan, W. F.; Jia, M. J.; Catal. Commun. 2011, 12, 721.

5. Li, D.; Fang, W. J.; Xing, Y.; Guo, Y. S.; Lin, R. S.; J. Hazard. Mater. 2009, 161, 1193

6. Gorobets, M. I.; Ataev, M. B.; Gafurov, M. M.; Kirillov, S. A.; J. Mol. Liq. 2015, 205, 98.

7. Aresta, M.; Galatola, M.; J. Clean. Prod. 1999, 3, 181.

8. Dong, W. S.; Zhou, X. S.; Xin, C. S.; Liu, C. L.; Liu, Z. T.; Appl. Catal., A 2008, 334, 100.

9. Kumar, P.; Srivastava, V. C.; Gläser, R.; With, P.; Mishra, I. M.; Powder Technol. 2017, 309, 13.

10. Kumar, P.; Kaur, R.; Verma, S.; Srivastava, V. C.; Mishra, I. M.; Fuel 2018, 220, 706.

11. Wu, X. M.; Kang, M.; Yin, Y. L.; Wang, F.; Zhao, N.; Xiao, F. K.; Wei, W.; Sun, Y. H.; Appl. Catal., A 2014, 473, 13.

12. Ding, Y. J.; Kong, A. G.; Zhang, H. Q.; Shen, H. H.; Sun, Z. D.; Huang, S. P. D.; Shan, Y. K.; Appl. Catal., A 2013, 455, 58.

13. Wenger, J.; Porter, E.; Collins, E.; Treacy, J.; Sidebottom, H.; Chemosphere 1999, 38, 1197.

14. Dakka, J. M.; Miseo, S.; Soled, S. L.; Santiesteban, J. G.; Baumgartner, J. E.; Vliet, M. C. A. V.; Sheldon, R. A.; US pat. 7,718,564 2010.

15. Zhao, X. S.; Lu, G. Q.; Millar, G. J.; Ind. Eng. Chem. Res. 1996, 35 , 2075.

16. Ghorbani, F.; Younesi, H.; Mehraban, Z.; Celik, M. S.; Ghoreyshi, A. A.; Anbia, M.; J. Taiwan Inst. Chem. Eng. 2013, 44, 821.

17. Karthik, M.; Liang-Yi, L.; Bai, H.; Microporous Mesoporous Mater. 2009, 117, 153.
18. Noreña-Franco, L.; Hernandez-Perez, I.; Aguilar-Pliego, J.; MaubertFranco A.; Catal. Today 2002, 75, 189.

19. Qiu, J.; Zhuang, K.; Lu, M.; Xu, B. L.; Fan, Y. N.; Catal. Commun. 2013, 31, 21.

20. Deshmane, V. G.; Abrokwah, R. Y.; Kuila, D.; Int. J. Hydrogen Energy 2015, 40, 10439.

21. Abu-Zied, B. M.; Schwieger, W.; Asiri, A. M.; Microporous Mesoporous Mater. 2015, 218, 153.

22. Biz, S.; Occelli, M. L.; Catal. Rev. 1998, 40, 329.

23. Kong, Y.; Jiang, S. Y.; Wang, J.; Wang, S. S.; Yan, Q. J.; Lu, Y. N.; Microporous Mesoporous Mater. 2005, 86, 191.

24. Hernández Cedeño, G.; Silva-Rodrigo, R.; Guevara-Lara, A.; MeloBanda, J. A.; Reyes de la Torre, A. I.; MorteoFlores, F.; Castillo-Mares, A.; Catal. Today 2016, 271, 64.

25. Hassanzadeh-Tabrizi, S. A.; Bigham, A.; Rafienia, M.; Mater. Sci. Eng., C 2016, 58, 737.

26. Sing, K. S. W.; Everett, D. H.; Haul, R. A. W.; Moscou, L.; Pierotti, R. A.; Rouquérol, J.; Siemieniewska, T.; Pure Appl. Chem. 1985, 57, 603.

27. Abrokwah, R. Y.; Deshmane, V. G.; Kuila, D.; J. Mol. Catal. A: Chem. 2016, 425, 10 .

28. Liu, D. P.; Quek, X. Y.; Cheo, W. N. E.; Lau, R.; Borgna, A.; Yang, Y. H.; J. Catal. 2009, 266, 380.

29. Brahmi, L.; Ali-Dahmane, T.; Hamacha, R.; Hacini, S.; J. Mol. Catal. A: Chem. 2016, 423, 31.

30. Yang, F.; Gao, S. Y.; Xiong, C. R.; Wang, H. Q.; Chen, J.; Kong, Y.; Chin. J. Catal. 2015, 36, 1035.

31. Shekouhy, M.; Moaddeli, A.; Khalafi-Nezhad, A.; J. Ind. Eng. Chem. 2017, 50, 41.

32. Wang, B.; Wen, C.; Cui, Y. Y.; Chen, X. Dong, Y. Dai, W. L.; RSC Adv. 2015, 5, 29040.

33. Ling, Y. H.; Long, M. C.; Hu, P. D.; Chen, Y.; Huang, J. W.; J. Hazard. Mater. 2014, 264, 195.

34. Stekrova, M.; Zdenkova, R.; Vesely, M.; Vyskocilova, E.; Cerveny, L.; Materials 2014, 7, 2650.

35. Bordiga, S.; Lamberti, C.; Bonino, F.; Travert, A.; Thibault-Starzyk, F.; Chem. Soc. Rev. 2015, 44, 7262.

36. Ambursa, M. M.; Sudarsanam, P.; Voon, L. H.; Hamid, S. B. A.; Bhargava, S. K.; Fuel Process. Technol. 2017, 162, 87.

37. Djinovi, P.; Batista, J.; Pintar, A.; Appl. Catal., A 2008, 347, 23.

38. Ganiyu, S. A.; Alhooshani, K.; Ali, S. A.; Appl. Catal., B 2017, 203, 428.

39. Luo, X. R.; Liu, P. F.; Li, J.; Li, Z.; He, K.; Appl. Surf. Sci. 2014, 307, 382.

40. Wang, B.; Cui, Y. Y.; Wen, C.; Chen, X.; Dong, Y.; Dai, W.; Appl. Catal., A 2016, 509, 66.

41. Csicsery, S. M.; Zeolites 1984, 4, 202.

42. Fabiano, D. P.; Hamad, B.; Cardoso, D.; Essayem, N.; J. Catal. 2010, 276, 190

43. Wen, C.; Li, F. Q.; Cui, Y. Y.; Dai, W. L.; Fan, K. N.; Catal. Today 2014, 233, 117.

44. Chang, T. C.; Chen, J. J.; Yeh, C. T.; J. Catal. 1985, 96, 51. 